\title{
(2) OPEN ACCESS \\ Neonatal admission and mortality in babies born in UK alongside midwifery units: a national population- based case-control study using the UK Midwifery Study System (UKMidSS)
}

\author{
Rachel Rowe (1) , ${ }^{1}$ Aung Soe, ${ }^{2}$ Marian Knight $(1),{ }^{1}$ Jennifer J Kurinczuk, ${ }^{1}$ UK Midwifery \\ Study System (UKMidSS)
}

\begin{abstract}
${ }^{1}$ National Perinatal Epidemiology Unit, Nuffield Department of Population Health, University of Oxford, Oxford, UK

${ }^{2}$ Oliver Fisher Neonatal Intensive Care Unit, Medway Maritime Hospital, Medway NHS Foundation Trust, Gillingham, UK
\end{abstract}

\section{Correspondence to} Associate Professor Rachel Rowe, National Perinata Epidemiology Unit, Nuffield Department of Population Health, University of Oxford, Oxford OX3 7LF, UK; rachel.rowe@npeu.ox.ac.uk

Received 3 March 2020 Revised 14 July 2020 Accepted 21 August 2020 Published Online First 30 October 2020

\section{Check for updates}

(C) Author(s) (or their employer(s)) 2021. Re-use permitted under CC BY. Published by BMJ.

To cite: Rowe $R$, Soe $A$, Knight M, et al. Arch Dis Child Fetal Neonatal Ed 2021:106:F194-F203.

\section{ABSTRACT \\ Objectives To determine the incidence of and risk factors for neonatal unit admission, intrapartum stillbirth or neonatal death without admission, and describe outcomes, in babies born in an alongside midwifery unit (AMU).}

Design National population-based case-control study. Method We used the UK Midwifery Study System to identify and collect data about 1041 women who gave birth in AMUs, March 2017 to February 2018, whose babies were admitted to a neonatal unit or died (cases) and 1984 controls from the same AMUs. We used multivariable logistic regression, generating adjusted OR (aOR) with 95\% Cls, to investigate maternal and intrapartum factors associated with neonatal admission or mortality.

Results The incidence of neonatal admission or mortality following birth in an AMU was 1.2\%, comprising neonatal admission (1.2\%) and mortality $(0.01 \%)$. White 'other' ethnicity (aOR=1.28; $95 \%$ $\mathrm{Cl}=1.01$ to 1.63$)$; nulliparity $(\mathrm{aOR}=2.09 ; 95 \% \mathrm{Cl}=1.78$ to 2.45 ); $\geq 2$ previous pregnancies $\geq 24$ weeks gestation $(\mathrm{aOR}=1.38 ; 95 \% \mathrm{Cl}=1.10$ to 1.74$)$; male sex $(\mathrm{aOR}=1.46 ; 95 \% \mathrm{Cl}=1.23$ to 1.75$)$; maternal pregnancy problem $(\mathrm{aOR}=1.40 ; 95 \% \mathrm{Cl}=1.03$ to 1.90); prolonged ( $\mathrm{aOR}=1.42 ; 95 \% \mathrm{Cl}=1.01$ to 2.01 ) or unrecorded $(\mathrm{aOR}=1.38 ; 95 \% \mathrm{Cl}=1.05$ to 1.81$)$ second stage duration; opiate use $(\mathrm{aOR}=1.31 ; 95 \% \mathrm{Cl}=1.02$ to 1.68); shoulder dystocia (aOR $=5.06 ; 95 \% \mathrm{Cl}=3.00$ to 8.52); birth weight $<2500 \mathrm{~g}(\mathrm{aOR}=4.12 ; 95 \% \mathrm{Cl}=1.97$ to 8.60$), 4000-4999 \mathrm{~g}(\mathrm{aOR}=1.64 ; 95 \% \mathrm{Cl}=1.25$ to 2.14) and $\geq 4500 \mathrm{~g}(\mathrm{aOR}=2.10 ; 95 \% \mathrm{Cl}=1.17$ to 3.76$)$, were independently associated with neonatal admission or mortality. Among babies admitted $(n=1038), 18 \%$ received intensive care. Nine babies died, six following neonatal admission. Sepsis (52\%) and respiratory distress (42\%) were the most common discharge diagnoses.

Conclusions The results of this study are in line with other evidence on risk factors for neonatal admission, and reassuring in terms of the quality and safety of care in AMUs.

\section{INTRODUCTION}

Most babies in high-income countries are born in hospital obstetric units (OU), ${ }^{12}$ but in the UK around $15 \%$ of births take place in midwifery-led

\section{What is already known on this topic?}

- National guidance recommends that women at low risk of complications should have a choice of planned birth setting.

- For low-risk women planned midwifery unit birth is as safe for babies and associated with reduced intervention, compared with planned hospital obstetric unit birth.

- Neonatal admission following birth in a midwifery unit, where most women are low risk, not induced and give birth vaginally, is a potential 'near-miss' event.

\section{What this study adds?}

- Around $1 \%$ of babies born in the UK alongside midwifery units are admitted to neonatal care, are stillborn or die soon after birth without admission.

- Few babies had diagnoses or outcomes indicative of serious intrapartum-related adverse outcome.

- Risk factors for neonatal admission or mortality identified in our study are known risk factors for adverse neonatal outcome in term infants in other settings.

settings. ${ }^{34}$ Around $80 \%$ of these are in alongside midwifery units (AMU), on the same site as an OU. For women at low risk of complications, planned birth in an AMU is associated with less intervention, ${ }^{5}$ including a $60 \%$ reduction in the likelihood of caesarean section, with no difference in neonatal outcomes, compared with planned birth in an OU. ${ }^{6}$ Most women planning birth in AMUs are at low risk, but around 4\% have pre-existing risk factors ${ }^{67}$; many AMUs now explicitly admit women with selected risk factors. ${ }^{89}$

National guidance recommends transfer to an OU when complications occur during labour in a midwifery-led setting. ${ }^{10}$ However, around $40 \%$ of adverse perinatal outcomes in births planned in midwifery-led settings occur in births in the planned setting, that is, when no transfer took place. ${ }^{6}$ Most babies admitted to neonatal care are born in OUs. 
Neonatal admission, or death without admission, following birth in an AMU, where most women are at low risk of complications, labour spontaneously and give birth vaginally, is a potential indicator of a 'near-miss' or adverse outcome event where different management might have made a difference to outcome. Factors associated with term admission and reasons for admission are well-documented, ${ }^{11-15}$ but there is no evidence about admission following birth in a midwifery-led setting. This study aimed to: (i) determine the incidence of and risk factors for admission to neonatal care, intrapartum stillbirth or neonatal death without admission, in babies born in an AMU and (ii) describe reasons for neonatal admission.

\section{METHODS}

Study design

We carried out a national, population-based, case-control study.

\section{Cases and controls}

We identified and collected data about women who gave birth in an AMU in the UK between 1 March 2017 and 28 February 2018, and whose baby was admitted to a neonatal unit, for at least 4 hours, within 48 hours of birth or before discharge home or who was stillborn or died within 48 hours of birth without admission to neonatal care (cases). We refer to this outcome as 'neonatal admission or mortality'. Controls were the two women not meeting the case definition who gave birth in the same AMU immediately before each case.

\section{Data collection}

We collected data using the UK Midwifery Study System (UKMidSS), a national research infrastructure covering all 123 AMUs in all four countries of the UK. UKMidSS midwife 'reporters' in each AMU reported cases, and the number of AMU births, in response to monthly emails, and entered anonymised data directly from medical records using study-specific forms in a secure web-based environment. ${ }^{16}$

We compared the number of deaths reported for this study with those reported to national perinatal surveillance $\left(\right.$ MBRRACE-UK) ${ }^{17}$ in AMU births over the same period. Where this identified potentially 'missing' deaths, not reported to UKMidSS, we contacted UKMidSS and MBRRACE-UK reporters in the relevant units to cross-check using MBRRACE-UK and UKMidSS ID numbers (no identifiers were disclosed). Where a previously unreported case was identified, data were collected as described above.

\section{Data}

We considered maternal sociodemographic factors; pre-existing clinical characteristics and those arising during pregnancy and intrapartum and birth-related factors, as potential explanatory variables (online supplementary table S1) and collected the neonatal outcomes listed in online supplementary table S2.

\section{Analysis}

We estimated the incidence of neonatal admission or mortality (combined and separately) using the total reported births as the denominator, with $95 \%$ CIs.

We described characteristics of cases and controls, and neonatal outcomes for cases. We used unconditional logistic regression to investigate univariable associations between explanatory variables and the primary outcome, and built a multivariable model, calculating unadjusted OR and adjusted OR (aOR) with 95\% CI. Conditional logistic regression was not used since cases and

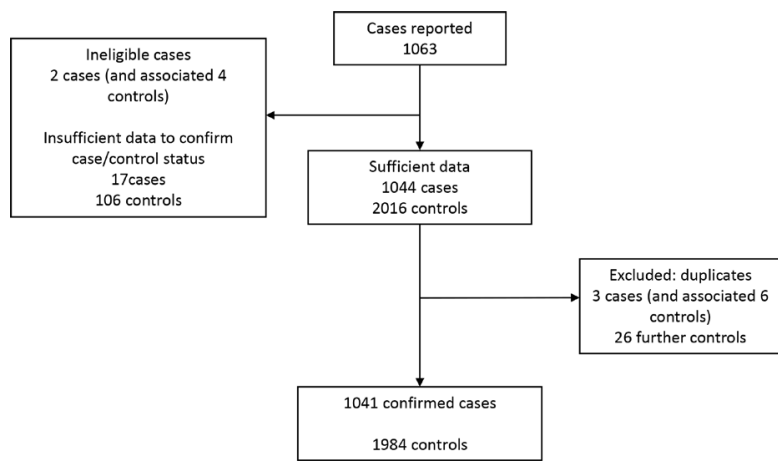

Figure 1 Reported and confirmed cases and controls with reasons for exclusion.

controls were 'convenience matched' on the basis of time of birth only. ${ }^{18}$ We used a prespecified conceptual framework approach to multivariable model building, adding variables to the model in stages from distal to proximal (maternal and pre-existing clinical characteristics first, followed by maternal clinical characteristics arising during pregnancy, maternal intrapartum factors and finally, birth-related factors). Variables were considered for inclusion in the model if $\mathrm{p}<0.05$ in the univariable analysis, or if univariable analyses indicated that their association with the outcome was confounded by another variable. The contribution of each variable to the fit of the data to the model was tested for significance using the Wald test, and variables for which $p<0.05$ were retained in the model. We used robust variance estimation to allow for the clustering of women within units.

In a post hoc analysis, we compared the highest level of care received and reasons for admission in centres where the number of cases reported or the incidence of admission was at or above the 95 th centile, with other centres, using the $\chi^{2}$ test.

Our approach to handling missing data, and sample size and power calculations are presented in online supplementary box S1.

We used Stata V.15SE for all analyses. ${ }^{19}$

\section{RESULTS}

\section{Response and incidence}

All 123 AMUs in the UK participated (100\% of eligible units), with a $99.8 \%$ response to monthly report requests.

In total, 1063 cases were reported (figure 1). There were 1041 confirmed cases, and 1984 controls, from a total of 87102 women giving birth in AMUs. Among the 1041 cases, two women had an intrapartum stillbirth and one woman's baby died after birth without admission to neonatal care. Six of the 1038 surviving babies admitted to neonatal care subsequently died. The incidence of neonatal admission or mortality following birth in an AMU was 1.2\% (95\% CI 1.1 to 1.3$)$, comprising neonatal admission (1.2\%) and mortality (0.01\%).

Overall, 110 out of 123 (85.4\%) AMUs in the UK reported at least one confirmed case during the study period. The incidence of neonatal admission or mortality in each AMU ranged from $0 \%$ to $4.2 \%$ (median $1.0 \%$; IQR $0.5 \%-1.6 \%$ ).

\section{Univariable analysis}

Among sociodemographic and pre-existing clinical characteristics of women, ethnicity, parity and previous pregnancy problems were statistically significantly associated with neonatal admission or mortality (table 1 ). Clinical characteristics arising during pregnancy that were statistically significantly associated 


\section{Original research}

Table 1 Sociodemographic, pre-existing and pregnancy-related clinical characteristics of women

\begin{tabular}{|c|c|c|c|c|c|c|c|}
\hline & \multicolumn{2}{|c|}{ Cases $n=1041$} & \multicolumn{2}{|c|}{ Controls $n=1984$} & \multicolumn{3}{|c|}{ Unadjusted analysis } \\
\hline & $\mathrm{n}$ & $\%$ & $\mathrm{n}$ & $\%$ & OR & $(95 \% \mathrm{Cl})$ & $P$ value \\
\hline Maternal age (years) & & & & & & & 0.30 \\
\hline Under 20 & 43 & 4.1 & 55 & 2.8 & 1.55 & (0.98 to 2.46 ) & \\
\hline $20-24$ & 177 & 17.0 & 325 & 16.4 & 1.08 & (0.85 to 1.37$)$ & \\
\hline $25-29$ & 312 & 30.0 & 619 & 31.2 & 1 & & \\
\hline $30-34$ & 342 & 32.9 & 628 & 31.7 & 1.08 & (0.89 to 1.32 ) & \\
\hline $35-39$ & 155 & 14.9 & 324 & 16.3 & 0.95 & (0.74 to 1.22 ) & \\
\hline$\geq 40$ & 12 & 1.2 & 33 & 1.7 & 0.72 & (0.40 to 1.30$)$ & \\
\hline Missing & 0 & & 0 & & & & \\
\hline Ethnic group & & & & & & & 0.004 \\
\hline White (UK and Ireland) & 641 & 61.6 & 1210 & 61.0 & 1 & & \\
\hline White (other) & 170 & 16.3 & 246 & 12.4 & 1.30 & (1.05 to 1.62 ) & \\
\hline Asian & 140 & 13.5 & 289 & 14.6 & 0.91 & (0.76 to 1.10$)$ & \\
\hline Black & 51 & 4.9 & 134 & 6.8 & 0.72 & (0.50 to 1.03 ) & \\
\hline Other & 39 & 3.8 & 105 & 5.3 & 0.70 & (0.46 to 1.06$)$ & \\
\hline Missing & 0 & & 0 & & & & \\
\hline Socioeconomic status & & & & & & & 0.06 \\
\hline Higher managerial, admin, prof & 301 & 28.9 & 540 & 27.2 & 1 & & \\
\hline Intermediate & 202 & 19.4 & 362 & 18.3 & 1.00 & (0.81 to 1.24$)$ & \\
\hline Routine and manual & 237 & 22.8 & 499 & 25.2 & 0.85 & (0.69 to 1.06$)$ & \\
\hline Unemployed/Student & 100 & 9.6 & 160 & 8.1 & 1.12 & (0.88 to 1.43$)$ & \\
\hline Employed, job unrecorded or uncodable & 66 & 6.3 & 123 & 6.2 & 0.96 & (0.70 to 1.33$)$ & \\
\hline Employment status not recorded & 135 & 13.0 & 300 & 15.1 & 0.81 & (0.65 to 1.00$)$ & \\
\hline Area deprivation quintile* & & & & & & & 0.29 \\
\hline First (least deprived) & 175 & 17.0 & 374 & 19.0 & 1 & & \\
\hline Second & 192 & 18.6 & 390 & 19.9 & 1.05 & (0.82 to 1.35 ) & \\
\hline Third & 211 & 20.5 & 409 & 20.8 & 1.10 & (0.87 to 1.40$)$ & \\
\hline Fourth & 242 & 23.5 & 408 & 20.8 & 1.27 & (0.98 to 1.64$)$ & \\
\hline Fifth (most deprived) & 210 & 20.4 & 383 & 19.5 & 1.17 & (0.92 to 1.49$)$ & \\
\hline Missing & 11 & & 20 & & & & \\
\hline Smoking status & & & & & & & 0.71 \\
\hline Non-smoker during pregnancy & 903 & 86.9 & 1720 & 86.7 & 1 & & \\
\hline Smoker during pregnancy & 125 & 12.0 & 235 & 11.8 & 1.01 & (0.80 to 1.28$)$ & \\
\hline Not recorded & 11 & 1.1 & 29 & 1.5 & 0.72 & (0.32 to 1.61$)$ & \\
\hline Missing & 2 & & 0 & & & & \\
\hline Previous pregnancies $\geq 24$ weeks & & & & & & & $<0.0001$ \\
\hline 0 & 523 & 50.2 & 704 & 35.5 & 1.98 & (1.70 to 2.31$)$ & \\
\hline 1 & 328 & 31.5 & 875 & 44.1 & 1 & & \\
\hline 2 & 137 & 13.2 & 280 & 14.1 & 1.31 & (1.03 to 1.65$)$ & \\
\hline 3 or more & 53 & 5.1 & 125 & 6.3 & 1.13 & (0.77 to 1.67$)$ & \\
\hline Missing & 0 & & 0 & & & & \\
\hline BMI at booking $\left(\mathrm{kg} / \mathrm{m}^{2}\right)$ & & & & & & & 0.44 \\
\hline$<18.5$ & 23 & 2.2 & 56 & 2.8 & 0.73 & (0.42 to 1.26$)$ & \\
\hline $18.5-24.9$ & 529 & 50.8 & 1063 & 53.6 & 0.88 & (0.75 to 1.05$)$ & \\
\hline $25-29.9$ & 296 & 28.4 & 526 & 26.5 & 1 & & \\
\hline $30-35.0$ & 89 & 8.6 & 154 & 7.8 & 1.03 & (0.76 to 1.38$)$ & \\
\hline$>35.0$ & 26 & 2.5 & 34 & 1.7 & 1.36 & (0.78 to 2.37 ) & \\
\hline Not recorded & 78 & 7.5 & 151 & 7.6 & 0.92 & (0.73 to 1.16$)$ & \\
\hline Missing & 0 & & 0 & & & & \\
\hline Pre-existing medical risk factors† & & & & & & & 0.69 \\
\hline None & 1026 & 98.6 & 1956 & 98.7 & 1 & & \\
\hline One or more & 15 & 1.4 & 25 & 1.3 & 1.14 & (0.59 to 2.21$)$ & \\
\hline Missing & 0 & & 3 & & & & \\
\hline Problems in a previous pregnancy (multipa & vomen & & & & & & 0.03 \\
\hline None & 494 & 95.4 & 1247 & 97.4 & 1 & & \\
\hline One or more & 24 & 4.6 & 33 & 2.6 & 1.83 & (1.05 to 3.20$)$ & \\
\hline
\end{tabular}


Table 1 Continued

\begin{tabular}{|c|c|c|c|c|c|c|c|}
\hline & \multicolumn{2}{|c|}{ Cases $n=1041$} & \multicolumn{2}{|c|}{ Controls $n=1984$} & \multicolumn{3}{|c|}{ Unadjusted analysis } \\
\hline & $\mathrm{n}$ & $\%$ & $\mathbf{n}$ & $\%$ & OR & $(95 \% \mathrm{Cl})$ & $P$ value \\
\hline Missing & 0 & & 0 & & & & \\
\hline Current pregnancy maternal problem§ & & & & & & & 0.07 \\
\hline None & 950 & 91.6 & 1847 & 93.4 & 1 & & \\
\hline One or more & 87 & 8.4 & 131 & 6.6 & 1.29 & (0.98 to 1.71$)$ & \\
\hline Missing & 4 & & 6 & & & & \\
\hline Current pregnancy fetal problem & & & & & & & 0.03 \\
\hline None & 1018 & 98.2 & 1960 & 99.1 & 1 & & \\
\hline One or more & 19 & 1.8 & 18 & 0.9 & 2.03 & (1.06 to 3.88$)$ & \\
\hline Missing & 4 & & 6 & & & & \\
\hline Sex of baby & & & & & & & $<0.0001$ \\
\hline Male & 630 & 60.8 & 1009 & 50.9 & 1.50 & (1.27 to 1.76$)$ & \\
\hline Female & 406 & 39.2 & 973 & 49.1 & 1 & & \\
\hline Missing & 5 & & 2 & & & & \\
\hline Gestation at birth (weeks) & & & & & & & 0.20 \\
\hline $36-37$ & 37 & 3.6 & 50 & 2.5 & 1.46 & (0.91 to 2.35 ) & \\
\hline 38 & 127 & 12.3 & 213 & 10.8 & 1.18 & (0.90 to 1.53$)$ & \\
\hline 39 & 295 & 28.5 & 623 & 31.5 & 0.93 & (0.78 to 1.12 ) & \\
\hline 40 & 362 & 34.9 & 714 & 36.1 & 1 & & \\
\hline $41-42$ & 216 & 20.8 & 380 & 19.2 & 1.12 & (0.94 to 1.34 ) & \\
\hline Missing & 4 & & 4 & & & & \\
\hline $\begin{array}{l}\text { *Area deprivation quintiles created usin } \\
\text { †Essential hypertension; confirmed card } \\
\text { łUnexplained stillbirth/neonatal death } \\
\text { transfusion; shoulder dystocia; previous } \\
\S G B S ; B M I>35 \mathrm{~kg} / \mathrm{m}^{2} \text {; post-term pregn } \\
\text { diabetes; other. } \\
\text { १Malpresentation; small for gestational } \\
\text { BMI, body mass index; GBS, group B str }\end{array}$ & $\begin{array}{l}\text { in low- } \\
\text { e; throm } \\
\text { s death } \\
\text { sectior } \\
\text { clamps } \\
\text { ced feta } \\
\text { s; PPH, }\end{array}$ & $\begin{array}{l}\text { ilies me } \\
\text { disorde } \\
\text { trapart } \\
y \text {-induc } \\
\text { s; fetal } \\
\text { haemo }\end{array}$ & $\begin{array}{l}\text { tibodie } \\
\text { previo } \\
\text { ion; pre }\end{array}$ & $\begin{array}{l}\text { idism; } \\
\text { our rup }\end{array}$ & $\begin{array}{l}\text { nal dise } \\
\text { alopathy } \\
\text { nbranes }\end{array}$ & $\begin{array}{l}\text { pilepsy. } \\
\text { ary PPH requirin } \\
\text { tance misuse/alc }\end{array}$ & stational \\
\hline
\end{tabular}

with neonatal admission or mortality were: current pregnancy fetal problem and sex of the baby (table 1). Details of medical risk factors, and pregnancy problems are shown in online supplemental tables S3 and S4.

Labour-related factors significantly associated with neonatal admission or mortality were: fetal complication at the start of labour care, stage of labour at admission, prolonged second stage of labour, immersion in water, opiates for pain relief, fetal heart rate concerns or other fetal complications identified during labour and consulting an obstetrician for fetal compromise (table 2). Details of complications are shown in online supplemental tables S5-S7. All four birth-related factors: shoulder dystocia, birth weight, birth in water and mode of birth were statistically significantly associated with neonatal admission or mortality (table 2).

\section{Multivariable analysis: factors associated with neonatal admission or mortality}

Multivariable analysis identified white 'other' ethnicity; nulliparity; two or more previous pregnancies $\geq 24$ weeks' gestation; male sex; maternal current pregnancy problem (most common group B streptococcus (GBS) and body mass index (BMI)) $>35$ $\mathrm{kg} / \mathrm{m}^{2}$, see online supplemental table $\mathrm{S} 2$ ); prolonged or unrecorded duration of second stage of labour; opiates during labour; shoulder dystocia and birth weight $<2500 \mathrm{~g}, 4000-4999 \mathrm{~g}$ and $\geq 4500 \mathrm{~g}$, as independently associated with neonatal admission or mortality (table 3 ).

\section{Neonatal outcomes}

Around three-quarters (78\%) of the cases admitted to neonatal care were admitted from the birth room, rather than from the postnatal ward (table 4 ). Less than half (43\%) received any neonatal resuscitation and in around $80 \%$ of those this comprised stimulation/positioning, inflation breaths and oxygen/ventilation breaths only. Among cases who were resuscitated, 17\% were intubated and $2 \%$ received neonatal resuscitation drugs. Around one in five cases (18\%) who were admitted to neonatal care received intensive care. The most common reasons for admission were respiratory problems and suspected infection, and this was reflected in diagnoses on discharge.

Centres with high numbers of cases

Compared with other centres, in centres with more cases or higher incidence, a higher proportion of babies received special care as the highest level of neonatal care (64\% vs 48\%, p<0.001), fewer babies were admitted because of respiratory problems $(60 \%$ vs $73 \%, \mathrm{p}<0.0001)$ and more babies were admitted with suspected infection $(52 \%$ vs $40 \%, \mathrm{p}=0.001)$ (online supplemental table S8).

\section{DISCUSSION}

Around 1\% of babies born in UK AMUs during the study period were admitted to neonatal care, stillborn or died within 48 hours of birth without admission. Less than half of the babies admitted to neonatal care required resuscitation and in around $80 \%$ of those this comprised stimulation/positioning, inflation breaths 


\section{Original research}

Table 2 Labour and birth-related factors

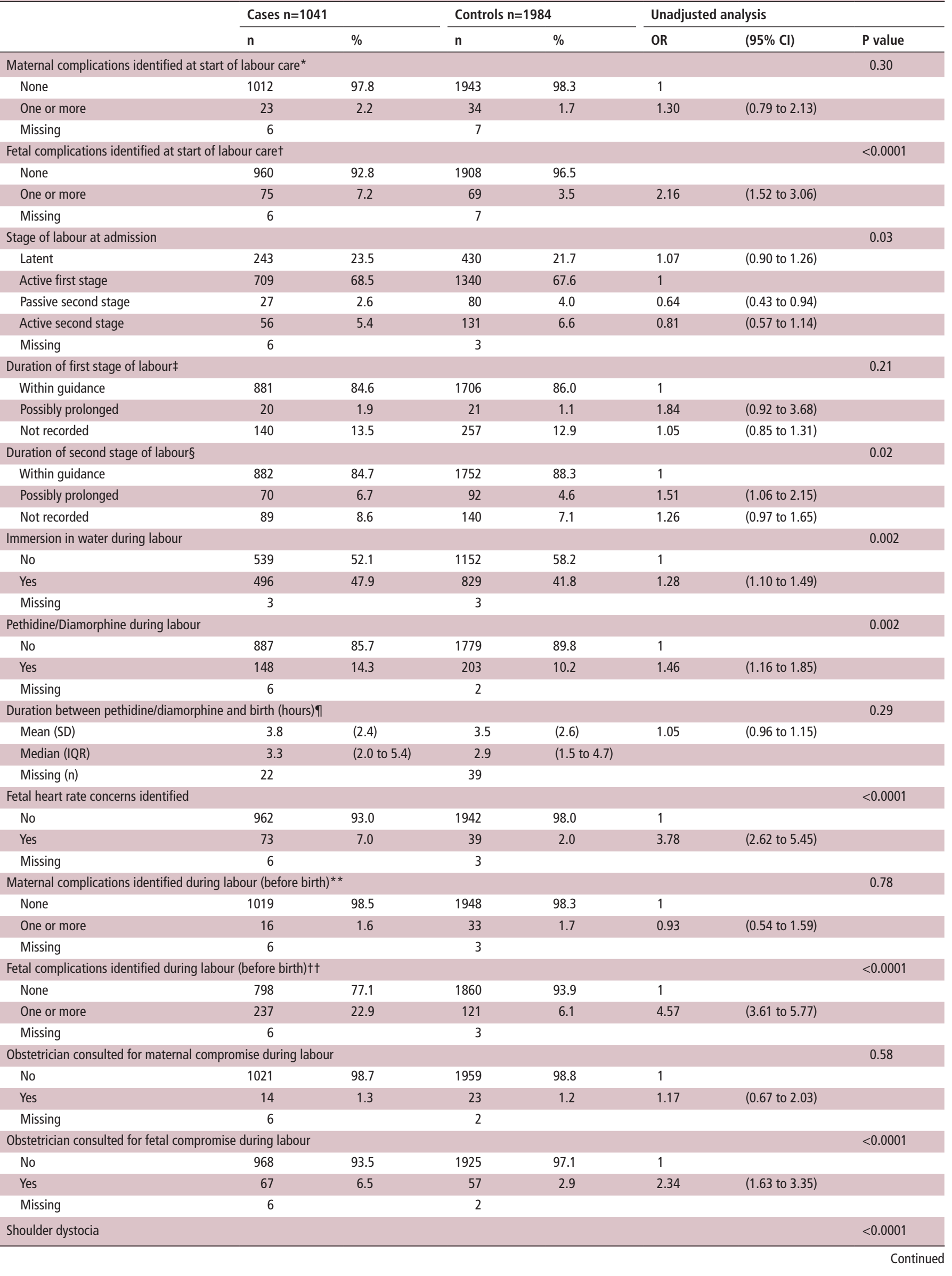


Table 2 Continued

\begin{tabular}{|c|c|c|c|c|c|c|c|}
\hline & \multicolumn{2}{|c|}{ Cases $n=1041$} & \multicolumn{2}{|c|}{ Controls $n=1984$} & \multicolumn{3}{|c|}{ Unadjusted analysis } \\
\hline & $\mathbf{n}$ & $\%$ & $\mathrm{n}$ & $\%$ & OR & $(95 \% \mathrm{Cl})$ & $P$ value \\
\hline No & 972 & 93.9 & 1958 & 98.8 & 1 & & \\
\hline Yes & 63 & 6.1 & 24 & 1.2 & 5.29 & (3.27 to 8.55$)$ & \\
\hline Missing & 6 & & 2 & & & & \\
\hline Birth weight (g) & & & & & & & $<0.0001$ \\
\hline$<2500$ & 25 & 2.4 & 12 & 0.6 & 4.65 & (2.34 to 9.24 ) & \\
\hline 2500-2999 & 130 & 12.6 & 233 & 11.7 & 1.25 & (0.95 to 1.63$)$ & \\
\hline $3000-3499$ & 383 & 37.0 & 855 & 43.2 & 1 & & \\
\hline 3500-3999 & 330 & 31.9 & 672 & 33.9 & 1.10 & (0.90 to 1.33 ) & \\
\hline $4000-4499$ & 137 & 13.2 & 183 & 9.2 & 1.67 & (1.29 to 2.16$)$ & \\
\hline$\geq 4500$ & 31 & 3.0 & 26 & 1.3 & 2.66 & (1.57 to 4.52$)$ & \\
\hline Missing & 5 & & 3 & & & & \\
\hline Birth in water & & & & & & & 0.01 \\
\hline No & 789 & 76.2 & 1425 & 71.9 & 1 & & \\
\hline Yes & 246 & 23.8 & 557 & 28.1 & 0.80 & (0.67 to 0.95$)$ & \\
\hline Missing & 6 & & 2 & & & & \\
\hline Mode of birth & & & & & & & 0.03 \\
\hline Spontaneous vertex & 1014 & 98.0 & 1962 & 99.0 & 1 & & \\
\hline Vaginal breech $\ddagger \ddagger$ & 8 & 0.8 & 1 & 0.1 & 15.48 & (1.87 to 128.32 ) & \\
\hline Instrumental & 13 & 1.3 & 18 & 0.9 & 1.40 & (0.62 to 3.13 ) & \\
\hline Missing & 6 & & 3 & & & & \\
\hline
\end{tabular}

*Maternal tachycardia; hypertension; proteinuria; maternal fever; vaginal blood loss; prolonged membrane rupture; pain differing from contractions.

tSignificant meconium; non-significant meconium; abnormal presentation; high/free floating head; suspected fetal growth restriction/macrosomia; suspected anhydramnios/ polyhydramnios; fetal heart rate abnormality; fetal heart rate decelerations; reduced fetal movements in last 24 hours.

\#From start of active first stage to start of active second stage: within guidance $\leq 12$ hours (nulliparous and multiparous); possibly prolonged $>12$ hours (nulliparous and multiparous).

§From start of active second stage to birth: within guidance $\leq 2$ hours (nulliparous), $\leq 1$ hour (multiparous); possibly prolonged $>2$ hours (nulliparous), $>1$ hour (multiparous).

IIn those who received pethidine/diamorphine.

**Maternal tachycardia; hypertension; maternal fever; vaginal blood loss; prolonged membrane rupture; pain differing from contractions.

††Significant meconium; confirmed/suspected first stage delay; confirmed/suspected second stage delay; obstetric emergency; abnormal presentation; transverse/oblique lie; high/free floating head; fetal heart rate abnormality; fetal heart rate decelerations.

$\ddagger \ddagger$ All vaginal breech births were undiagnosed before admission. One woman had a precipitate birth, shortly after admission. In the remaining eight, abnormal presentation was noted on admission or during labour and five women were seen by an obstetrician in the AMU.

$\mathrm{AMU}$, alongside midwifery unit.

and oxygen/ventilation breaths only. The most common reasons for admission were respiratory problems and suspected infection; this was reflected in discharge diagnoses. We found significant variation between units in rates and reasons for admission.

National statistics show that the overall incidence of neonatal admission in term babies is around $6 \%{ }^{1}$ and the incidence of intrapartum-related stillbirth or neonatal death at term is 0.28 per 1000 total births..$^{20}$ The lower incidence of these outcomes found in our study reflects the predominantly 'low risk' characteristics of the study population.

Babies of women with identified maternal pregnancy complications were 1.4 times more likely to be admitted to neonatal care. In line with other evidence, ${ }^{7}$ the most common of these complications were GBS colonisation and BMI $>35 \mathrm{~kg} / \mathrm{m}^{2}$. National guidance advises that women with a BMI $>35 \mathrm{~kg} / \mathrm{m}^{2}$, and those with GBS for whom antibiotics in labour would be recommended, should be advised to plan birth in an OU rather than a midwifery-led setting, the latter group so they can receive intrapartum antibiotic prophylaxis. ${ }^{10} 21$ Almost half of UK midwifery units now report admitting women who require antibiotics for $\mathrm{GBS}^{9}$ and admission of women with a BMI $>35 \mathrm{~kg} /$ $\mathrm{m}^{2}$ is also widespread. 'Higher risk' women in AMUs are more likely to be transferred before birth than women at 'low risk' of complications, but around $70 \%$ of 'higher risk' women admitted to AMUs give birth there without transfer. ${ }^{7}$ Planned birth in an AMU is associated with a significant reduction in the likelihood of having a Caesarean section compared with planned OU birth, ${ }^{6}$ and there is evidence of good outcomes for women with higher BMI in AMUs. ${ }^{8}$ Individual care plans are recommended for women at 'higher risk' of complications who plan to give birth outside an OU. ${ }^{10}$

Even in term appropriately grown babies, boys are more likely than girls to have lower Apgar scores, need neonatal resuscitation, develop respiratory problems and be admitted for neonatal care. ${ }^{22}$ Our finding, that boys were almost 1.5 times more likely than girls to be admitted for neonatal care, in a population in which $99 \%$ of women had a spontaneous vaginal birth, suggest that these differences are not explained by an increased risk of instrumental or operative birth, ${ }^{22}$ and are independent of birth weight.

Evidence about the duration of labour and neonatal outcomes is mixed, ${ }^{23}$ but recent studies point to an increased risk of adverse neonatal outcomes with prolonged second stage of labour. ${ }^{152425}$ We found that the likelihood of neonatal admission or mortality was 1.4 times higher when the second stage of labour was 'possibly prolonged'. ${ }^{10}$ Given available data it was not possible to determine why these women were not transferred to an $\mathrm{OU}$, as national guidance recommends, nor whether the outcome for the baby would have been different had transfer taken place. For some women, for example, free text comments indicated 
Table 3 Factors associated with neonatal admission or mortality

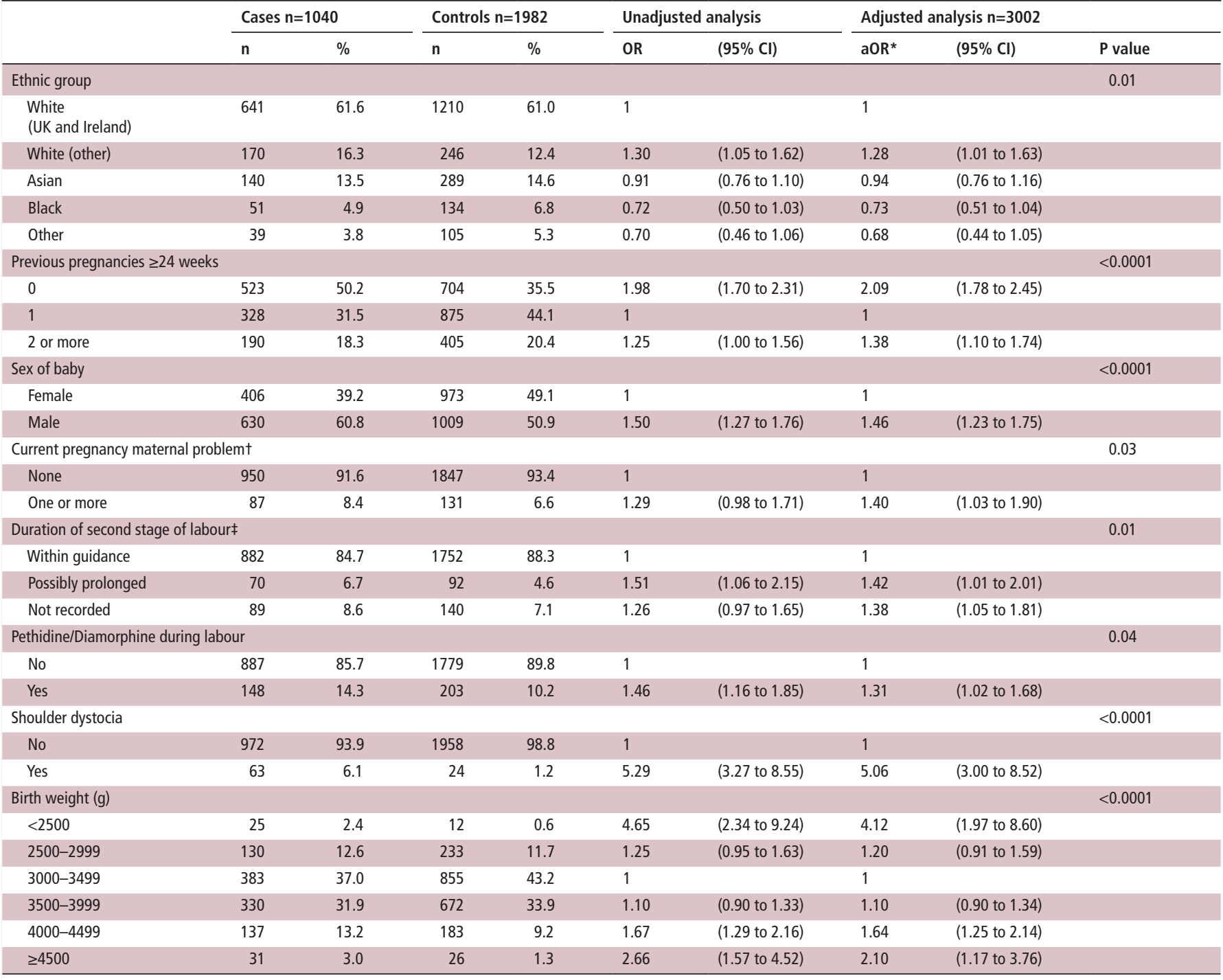

${ }^{*}$ Adjusted for all other variables in the model.

†GBS; BMI >35 kg/m²; post-term; pre-eclampsia/pregnancy-induced hypertension; preterm prelabour rupture of membranes; substance misuse/alcohol; gestational diabetes.

$\neq$ From start of active second stage to birth: within guidance $\leq 2$ hours (nulliparous), $\leq 1$ hour (multiparous); possibly prolonged $>2$ hours (nulliparous), $>1$ hour (multiparous).

BMI, body mass index; GBS, group B streptococcus.

that when concerns were identified late in labour an obstetrician attended the AMU to expedite birth, in preference to transfer, but available data did not permit further investigation. This might also explain at least some of the 31 instrumental births in an AMU in our study. Free text comments also indicated that, for some women, fetal concerns such as significant meconium and fetal heart decelerations were only identified in advanced labour or close to the time of birth. This might explain why these woman were not transferred, as recommended by national guidance ${ }^{10}$ however the extent to which this also explained the lack of consultation with an obstetrician, seen in several cases, was not clear.

Opioids are widely used for pain relief in labour, ${ }^{26}$ but are associated with neonatal respiratory depression. ${ }^{27} 28$ In line with other studies, ${ }^{1529}$ we found that the likelihood of neonatal admission or mortality was 1.3 times higher in babies of women who used opioids for pain relief in labour.

Our study confirms low $(<2500 \mathrm{~g})$ and high $(>4000 \mathrm{~g})$ birth weight as independent risk factors for adverse neonatal outcome. ${ }^{29-32}$ Fetal macrosomia is a risk factor for shoulder dystocia. ${ }^{33}$ Almost half of the cases with shoulder dystocia in our study had a birth weight $>4000 \mathrm{~g}$, but shoulder dystocia was associated with a fivefold increase in the likelihood of neonatal admission after adjusting for birth weight. Shoulder dystocia is a risk factor for birth trauma injuries, ${ }^{35}$ but in our study only a small proportion of the babies with documented shoulder dystocia had a discharge diagnosis of birth injury.

Finally, there are national initiatives aimed at reducing unnecessary neonatal admissions, avoiding separation of mother and baby, and standardising admission criteria, ${ }^{13} 36$ and some evidence that the provision of transitional care is increasing. ${ }^{4}$ Our study provides further evidence of variation in local neonatal unit admission policies, ${ }^{14}$ with significant variation between units in admission rates and reasons for admission.

This was a national population-based study, which reduces the risk of bias associated with local, hospital-based studies. All eligible units participated, with over 99\% response to monthly report requests and complete data returned for over $95 \%$ of reported cases, reducing the possibility of selection bias. There are nevertheless some potential limitations. We aimed to identify 


\section{Table 4 Neonatal outcomes}

\begin{tabular}{|c|c|c|c|c|}
\hline & \multicolumn{2}{|c|}{ Cases $\mathrm{n}=1041$} & \multicolumn{2}{|c|}{ Controls $n=1984$} \\
\hline & $\mathrm{n}$ & $\%$ & $\mathrm{n}$ & $\%$ \\
\hline \multicolumn{5}{|l|}{ Apgar score $<7$ at $5 \mathrm{~min}$} \\
\hline Yes & 222 & 21.5 & 10 & 0.5 \\
\hline Missing & 7 & & 2 & \\
\hline \multicolumn{5}{|l|}{ Neonatal resuscitation } \\
\hline Yes & 448 & 43.2 & 51 & 2.6 \\
\hline Missing & 5 & & 2 & \\
\hline \multicolumn{5}{|c|}{$\begin{array}{l}\text { Type of resuscitation (among those who } \\
\text { received resuscitation) }\end{array}$} \\
\hline Stimulation & 375 & 83.7 & 47 & 92.2 \\
\hline $\begin{array}{l}\text { Positioning/Managing } \\
\text { airway }\end{array}$ & 362 & 80.8 & 27 & 52.9 \\
\hline Five inflation breaths & 386 & 86.2 & 31 & 60.8 \\
\hline Oxygen & 261 & 58.3 & 11 & 21.6 \\
\hline Ventilation breaths & 277 & 61.8 & 10 & 19.6 \\
\hline Intubation & 77 & 17.2 & 0 & \\
\hline Chest compression & 32 & 7.1 & 1 & 2.0 \\
\hline Neonatal resuscitation drug & 9 & 2.0 & 0 & \\
\hline \multicolumn{5}{|c|}{$\begin{array}{l}\text { Hierarchy of resuscitation (among those who received } \\
\text { resuscitation)* }\end{array}$} \\
\hline $\begin{array}{l}\text { Airway (A): stimulation/ } \\
\text { positioning only }\end{array}$ & 15 & 3.4 & 17 & 33.3 \\
\hline $\begin{array}{l}\text { Breathing } 1 \text { (B1): A or five } \\
\text { inflation breaths }\end{array}$ & 73 & 16.3 & 17 & 33.3 \\
\hline $\begin{array}{l}\text { Breathing } 2 \text { (B2): } \mathrm{A} \text { or } \mathrm{B} 1 \text { or } \\
\text { oxygen/ventilation breaths }\end{array}$ & 275 & 61.4 & 16 & 31.4 \\
\hline $\begin{array}{l}\text { Breathing } 3 \text { (B3): } \mathrm{A} \text { or } \mathrm{B} 1 \text { or } \\
\text { B2 or intubation }\end{array}$ & 51 & 11.4 & 0 & \\
\hline $\begin{array}{l}\text { Chest compression (C): A or } \\
B \text { or chest compression }\end{array}$ & 25 & 5.6 & 1 & 2.0 \\
\hline $\begin{array}{l}\text { Drugs: } A \text { or } B \text { or } C \text { or } \\
\text { neonatal drugs }\end{array}$ & 9 & 2.0 & 0 & \\
\hline \multicolumn{5}{|l|}{$\begin{array}{l}\text { Neonatal team consulted while } \\
\text { baby in midwifery unit }\end{array}$} \\
\hline Yes & 893 & 86.2 & 136 & 6.9 \\
\hline Missing & 5 & & 4 & \\
\hline \multicolumn{5}{|l|}{$\begin{array}{l}\text { Primary reason neonatal team } \\
\text { consulted }\end{array}$} \\
\hline Respiratory problems & 572 & 64.6 & 26 & 19.7 \\
\hline Suspected infection & 31 & 3.5 & 16 & 12.1 \\
\hline $\begin{array}{l}\text { Suspected perinatal } \\
\text { asphyxia }\end{array}$ & 89 & 10.1 & 14 & 10.6 \\
\hline Meconium aspiration & 54 & 6.1 & 20 & 15.2 \\
\hline Congenital anomaly & 18 & 2.0 & 12 & 9.1 \\
\hline Feeding problems & 18 & 2.0 & 4 & 3.0 \\
\hline Physical trauma/birth injury & 11 & 1.2 & 6 & 4.6 \\
\hline Other & 93 & 10.5 & 34 & 25.8 \\
\hline Missing & 7 & & 4 & \\
\hline \multicolumn{5}{|l|}{$\begin{array}{l}\text { Age of baby when neonatal } \\
\text { team first consulted (hours) }\end{array}$} \\
\hline Mean (SD) & 4.5 & $(7.2)$ & 6.9 & (10.6) \\
\hline Median (IQR) & 0.6 & (0.7 to 6.3 ) & 2.2 & (0.3 to 8.5 ) \\
\hline \multicolumn{5}{|l|}{ Skin to skin } \\
\hline Yes & 885 & 86.1 & 1921 & 97.2 \\
\hline Missing & 13 & & 7 & \\
\hline \multicolumn{5}{|l|}{ Initiation of breast feeding } \\
\hline Yes & 794 & 77.0 & 1622 & 82.0 \\
\hline Missing & 10 & & 6 & \\
\hline $\begin{array}{l}\text { Age of baby at neonatal } \\
\text { admission (hours) }\end{array}$ & $n=1038$ & & $n=13 t$ & \\
\hline Mean (SD) & 6.4 & (8.4) & 10.1 & $(14.4)$ \\
\hline Median (IQR) & 2.3 & (0.6 to 9.5 ) & 2.1 & (2.0 to 11.5 ) \\
\hline
\end{tabular}

Table 4 Continued

\begin{tabular}{lll} 
Cases $n=1041$ & & \multicolumn{2}{l}{ Controls $n=1984$} \\
$n n$ & $n$
\end{tabular}

\begin{tabular}{|c|c|c|}
\hline \multicolumn{3}{|l|}{$\begin{array}{l}\text { Where was baby admitted } \\
\text { from }\end{array}$} \\
\hline Birth room & 802 & 77.7 \\
\hline Postnatal ward & 230 & 22.3 \\
\hline Missing & 6 & \\
\hline \multicolumn{3}{|l|}{$\begin{array}{l}\text { Highest level of care baby } \\
\text { received }\end{array}$} \\
\hline Intensive care & 182 & 17.7 \\
\hline High dependency care & 319 & 31.0 \\
\hline Special care & 527 & 51.3 \\
\hline Missing & 10 & \\
\hline \multicolumn{3}{|l|}{ Reasons for admission‡ } \\
\hline Respiratory problems & 731 & 70.4 \\
\hline Suspected infection & 438 & 42.2 \\
\hline $\begin{array}{l}\text { Suspected perinatal } \\
\text { asphyxia }\end{array}$ & 102 & 9.8 \\
\hline Meconium aspiration & 86 & 8.3 \\
\hline Hypoglycaemia & 57 & 5.5 \\
\hline Congenital anomaly & 46 & 4.4 \\
\hline Feeding problems & 44 & 4.2 \\
\hline Jaundice & 32 & 3.1 \\
\hline Cardiac problems & 23 & 2.2 \\
\hline Pulse oximetry & 15 & 1.5 \\
\hline Abnormal movements & 14 & 1.4 \\
\hline Hypothermia & 13 & 1.3 \\
\hline Physical trauma/birth injury & 11 & 1.1 \\
\hline Maternal substance abuse & 6 & 0.6 \\
\hline Other§ & 32 & 3.1 \\
\hline \multicolumn{3}{|l|}{ Diagnoses on discharge $\ddagger$} \\
\hline Sepsis & 536 & 51.9 \\
\hline $\begin{array}{l}\text { Respiratory distress } \\
\text { syndrome }\end{array}$ & 429 & 41.6 \\
\hline Congenital pneumonia & 41 & 4.0 \\
\hline $\begin{array}{l}\text { Transient tachypnoea of the } \\
\text { newborn }\end{array}$ & 64 & 6.2 \\
\hline Pneumothorax & 18 & 1.7 \\
\hline $\begin{array}{l}\text { Hypoxic ischaemic } \\
\text { encephalopathy }\end{array}$ & 74 & 7.2 \\
\hline $\begin{array}{l}\text { Meconium aspiration } \\
\text { syndrome }\end{array}$ & 62 & 6.0 \\
\hline PPHN & 13 & 1.3 \\
\hline Hypoglycaemia & 63 & 6.1 \\
\hline Jaundice & 68 & 6.6 \\
\hline Feeding problems & 30 & 2.9 \\
\hline Birth injury & 8 & 0.8 \\
\hline Congenital anomaly & 56 & 5.4 \\
\hline Cardiac problems & 20 & 1.9 \\
\hline $\begin{array}{l}\text { Neonatal abstinence } \\
\text { syndrome/social }\end{array}$ & 4 & 0.4 \\
\hline Normal & 16 & 1.6 \\
\hline $\begin{array}{l}\text { Insufficient information/not } \\
\text { specified }\end{array}$ & 78 & 7.6 \\
\hline Other & 17 & 1.6 \\
\hline
\end{tabular}

*Mutually exclusive hierarchy in which each category includes those babies who received that type of resuscitation, excluding those who also received any resuscitation type higher in the hierarchy.

tThirteen babies in the control group were admitted to neonatal care for less than $<4$ hours. Other data for these 13 babies not shown because of small numbers.

¥More than one reason for admission/discharge diagnosis could be given. §other includes: shoulder dystocia, observation, skin rash, intrauterine growth restriction/low birth weight and reason not specified. 
all women whose baby was admitted to neonatal care or who died following birth in an AMU. We checked against deaths reported to MBRRACE-UK, so are confident that we are unlikely to have missed deaths, but had no other sources of data against which to validate other reported cases, so it is possible that we may have missed some admissions. We were dependent on anonymised routine data from medical records so did not have data on a number of factors of interest, including, for example, staffing levels, time of day, day of the week or whether there was an agreed plan for care of the woman in an AMU in the presence of risk factors.

\section{CONCLUSIONS}

The results of this study are broadly reassuring and in line with existing evidence about the quality and safety of care in AMUs. Relatively few babies had diagnoses of suspected asphyxia or meconium aspiration, which might be indicative of serious intrapartum-related adverse outcome. Many of the factors we identified as associated with neonatal admission or mortality are known risk factors for adverse neonatal outcome in term infants in other settings. Midwives should continue to practice in line with national guidance in relation to the management of risk factors and emerging complications in women labouring in AMUs.

Twitter Rachel Rowe @RachelRowe3, Marian Knight @Marianfknight and UK Midwifery Study System (UKMidSS) @NPEU_UKMidSS

Acknowledgements The authors would like to thank all the UKMidSS reporting midwives across the UK who responded to monthly report requests and entered data, and the MBRRACE-UK reporters who helped identify potentially 'missing' cases. The authors would also like to thank UKMidSS Research Midwives Paula Jenkins and Ginny Mounce for their contribution to managing data collection and supporting UKMidSS reporters.

Collaborators The UKMidSS Steering Group (in addition to RR, AS, MK and JJK): Mervi Jokinen (Chair), Royal College of Midwives; Catherine Williams (Vice Chair), Lay member; Meena Bhatia (from June 2019), Oxford University Hospitals NHS Foundation Trust; Jan Butler (until December 2018), Cambridge University Hospitals NHS Foundation Trust; Philippa Cox (from February 2019), Homerton University Hospital NHS Foundation Trust; Abi Holmes, Cardiff \& Vale University Health Board; Karen Joash (from June 2019), Imperial College Healthcare NHS Trust; Eddie Morris, Royal College of Obstetricians and Gynaecologists; Jackie O' Neill (from February 2019), Northern Health and Social Care Trust; Dharmintra Pasupathy (until February 2020), Guy's and St Thomas' NHS Foundation Trust; Rachel Plachcinski, lay member; Jane Rogers, University Hospitals Southampton NHS Foundation Trust; Julia Sanders, Cardiff and Vale University Health Boards; Anna Temke (February-December 2019), South Tees Hospitals NHS Foundation Trust; Phyllis Winters (until June 2019), NHS Tayside.

Contributors RR conceived the study and developed the protocol with input from JJK and MK. RR managed data collection, wrote the analysis plan and carried out analysis with input from JJK, MK, AS and the UKMidSS Steering Group. RR drafted the manuscript with input from all authors. All authors were involved in interpretation of data, review and revision of the draft manuscript and approval of the final version.

Funding This paper presents independent research arising from a National Institute for Health Research (NIHR) Post Doctoral Fellowship awarded to Rachel Rowe (PDF2014-07-006). The views expressed are those of the authors and not necessarily those of the NHS, the NIHR or the Department of Health and Social Care.

Competing interests RR, MK and JJK report grants from the National Institute for Health Research (NIHR) during the conduct of this study. AS has nothing to disclose.

Patient consent for publication Not required.

Ethics approval UKMidSS and this study received ethics approval from the National Research Ethics Service (NRES) Committee South West-Frenchay (REC ref. 15/SW/0166) in May 2015.

Provenance and peer review Not commissioned; externally peer reviewed.

Data availability statement Data are available on reasonable request. Requests for access to the dataset underlying our findings will be considered by the National Perinatal Epidemiology Unit Data Sharing Committee and should be address to the Director, Jennifer Kurinczuk, jenny.kurinczuk@npeu.ox.ac.uk in the first instance.
Supplemental material This content has been supplied by the author(s). It has not been vetted by BMJ Publishing Group Limited (BMJ) and may not have been peer-reviewed. Any opinions or recommendations discussed are solely those of the author(s) and are not endorsed by BMJ. BMJ disclaims all liability and responsibility arising from any reliance placed on the content. Where the content includes any translated material, BMJ does not warrant the accuracy and reliability of the translations (including but not limited to local regulations, clinical guidelines, terminology, drug names and drug dosages), and is not responsible for any error and/or omissions arising from translation and adaptation or otherwise.

Open access This is an open access article distributed in accordance with the Creative Commons Attribution 4.0 Unported (CC BY 4.0) license, which permits others to copy, redistribute, remix, transform and build upon this work for any purpose, provided the original work is properly cited, a link to the licence is given, and indication of whether changes were made. See: https://creativecommons.org/ licenses/by/4.0/.

\section{ORCID iDs}

Rachel Rowe http://orcid.org/0000-0003-2994-3240

Marian Knight http://orcid.org/0000-0002-1984-4575

\section{REFERENCES}

1 NMPA Project Team. National maternity and perinatal audit: clinical report 2019. Based on births in NHS maternity services between 1 April 2016 and 31 March 2017. London RCOG; 2019.

2 Shaw D, Guise J-M, Shah N, et al. Drivers of maternity care in high-income countries: can health systems support woman-centred care? Lancet 2016;388:2282-95.

3 Walsh D, Spiby H, Grigg CP, et al. Mapping midwifery and obstetric units in England. Midwifery 2018;56:9-16.

4 Blotkamp A. National maternity and perinatal audit: Organsiational report 2019. London NMPA Project Team, RCOG; 2019.

5 Scarf VL, Rossiter C, Vedam S, et al. Maternal and perinatal outcomes by planned place of birth among women with low-risk pregnancies in high-income countries: a systematic review and meta-analysis. Midwifery 2018:62:240-55.

6 Hollowell J, Puddicombe D, Rowe R. The birthplace national prospective cohort study: perinatal and maternal outcomes by planned place of birth. Birthplace in England research programme. Final report part 4. London NIHR Service Delivery and Organisation programme; 2011.

7 Hollowell J, Rowe R, Townend J, et al. The birthplace in England national prospective cohort study: further analyses to enhance policy and service delivery decision-making for planned place of birth. Health Services and Delivery Research 2015;3:1-264.

8 Rowe R, Knight M, Kurinczuk JJ, et al. Outcomes for women with BMl $>35 \mathrm{~kg} /$ $\mathrm{m} 2$ admitted for labour care to alongside midwifery units in the UK: A national prospective cohort study using the UK Midwifery Study System (UKMidSS). PLoS One 2018;13:e0208041.

9 Glenister C, Burns E, Rowe R. Local guidelines for admission to UK midwifery units compared with national guidance: a national survey using the UK midwifery study system (UKMidSS). PLoS One 2020;15:e0239311.

10 National Institute for Health and Care Excellence. Intrapartum care: care of healthy women and their babies during childbirth. NICE guideline CG190. London NICE; 2014.

11 Tracy SK, Tracy MB, Sullivan E. Admission of term infants to neonatal intensive care: a population-based study. Birth 2007;34:301-7.

12 Alkiaat $A$, Hutchinson $M$, Jacques $A$, et al. Evaluation of the frequency and obstetric risk factors associated with term neonatal admissions to special care units. Aust N Z J Obstet Gynaecol 2013:53:277-82.

13 NHS Improvement. Reducing harm leading to avoidable admission of full-term babies into neonatal units. findings and resources for improvement, 2017. Available: https:// improvement.nhs.uk/documents/764/Reducing_term_admissions_final.pdf

14 Battersby C, Michaelides S, Upton M, et al. Term admissions to neonatal units in England: a role for transitional care? A retrospective cohort study. BMJ Open 2017:7:e016050.

15 Burgess APH, Katz J, Pessolano J, et al. Determination of antepartum and intrapartum risk factors associated with neonatal intensive care unit admission. J Perinat Med 2016:44:589-96.

16 Rowe RE, Kurinczuk JJ, Hollowell J, et al. The UK midwifery study system (UKMidSS): a programme of work to establish a research infrastructure to carry out national studies of uncommon conditions and events in midwifery units. BMC Pregnancy Childbirth 2016;16:1-6.

17 National Perinatal Epidemiology Unit. MBRRACE-UK: mothers and babies: reducing risk through audits and Confidential enquiries across the UK, 2019. Available: https:// www.npeu.ox.ac.uk/mbrrace-uk [Accessed 14 Jan 2020].

18 Bland JM, Altman DG. Matching. BMJ 1994:309:1128.

19 StataCorp. Stata statistical software: release 15. College Station, TX: StataCorp LLC, 2017.

20 Draper ES, Kurinczuk JJ, Kenyon S. MBBRACE-UK 2017 perinatal Confidential enquiry: term, singleton, intrapartum stillbirth and intrapartum-related neonatal death. 
Leicester: The Infant Mortality and Morbidity Studies, Department of Health Sciences, University of Leicester, 2017.

21 Hughes RG, Brocklehurst P, Steer PJ, et al. Prevention of early-onset neonatal group B streptococcal disease: Green-top guideline No. 36. BJOG 2017;124:e280-305.

22 Dunn L, Prior T, Greer R, et al. Gender specific intrapartum and neonatal outcomes for term babies. Eur J Obstet Gynecol Reprod Biol 2015;185:19-22.

23 Altman MR, Lydon-Rochelle MT. Prolonged second stage of labor and risk of adverse maternal and perinatal outcomes: a systematic review. Birth 2006:33:315-22.

24 Altman M, Sandström A, Petersson G, et al. Prolonged second stage of labor is associated with low Apgar score. Eur J Epidemiol 2015;30:1209-15.

25 Sandström A, Altman M, Cnattingius S, et al. Durations of second stage of labor and pushing, and adverse neonatal outcomes: a population-based cohort study. J Perinatol 2017;37:236-42.

26 Bricker L, Lavender T. Parenteral opioids for labor pain relief: a systematic review. Am J Obstet Gynecol 2002;186:S94-109.

27 Wong CA. Advances in labor analgesia. International journal of women's health 2010;1:139-54.

28 Jones L, Othman M, Dowswell T, et al. Pain management for women in labour: an overview of systematic reviews. Cochrane Database Syst Rev 2012;3:CD009234.

29 Yi Wen P, Broom E, Flatley C, et al. Maternal demographic and intrapartum antecedents of severe neonatal outcomes at term. J Matern Fetal Neonatal Med 2020;33:1-6
30 Malin GL, Morris RK, Riley R, et al. When is birthweight at term abnormally low? A systematic review and meta-analysis of the association and predictive ability of current birthweight standards for neonatal outcomes. BJOG 2014;121:515-26.

31 Temerinac $D$, Chen $X$, Sütterlin $M$, et al. Influence of fetal birth weight on perinatal outcome in planned vaginal births. Arch Gynecol Obstet 2014;289:313-8.

32 Rossi AC, Mullin P, Prefumo F. Prevention, management, and outcomes of macrosomia: a systematic review of literature and meta-analysis. Obstet Gynecol Surv 2013;68:702-9.

33 Bahar AM. Risk factors and fetal outcome in cases of shoulder dystocia compared with normal deliveries of a similar birthweight. Br J Obstet Gynaecol 1996;103:868-72.

34 Ouzounian JG, Gherman RB. Shoulder dystocia: are historic risk factors reliable predictors? Am J Obstet Gynecol 2005;192:1933-5.

35 Gherman RB, Chauhan S, Ouzounian JG, et al. Shoulder dystocia: the unpreventable obstetric emergency with empiric management guidelines. Am J Obstet Gynecol 2006;195:657-72.

36 Scottish Government. The best start: a five-year forward plan for maternity and neonatal care in Scotland, 2017. Available: https://www.gov.scot/publications/beststart-five-year-forward-plan-maternity-neonatal-care-scotland-9781786527646/

37 HM Revenue \& Customs. Personal tax credits: children in low-income families local measure: 2014 snapshot as at 31 August 2014: 30 September 2016, 2016. Available: https://www.gov.uk/government/statistics/personal-tax-credits-children-in-lowincome-families-local-measure-2014-snapshot-as-at-31-august-2014-30-september2016 [Accessed 14 Jan 2020]. 